\title{
SiC fibre by chemical vapour deposition on tungsten filament
}

\author{
R V KRISHNARAO*, J SUBRAHMANYAM and S SUBBARAO \\ Defence Metallurgical Research Laboratory, Kanchanbagh, Hyderabad 500 058, India
}

MS received 26 December 2000; revised 15 March 2001

\begin{abstract}
A CVD system for the production of continuous SiC fibre was set up. The process of SiC coating on $19 \mu \mathrm{m}$ diameter tungsten substrate was studied. Methyl trichloro silane $\left(\mathrm{CH}_{3} \mathrm{SiCl}_{3}\right)$ and hydrogen reactants were used. Effect of substrate temperature $\left(1300-1500^{\circ} \mathrm{C}\right)$ and concentration of reactants on the formation of $\mathrm{SiC}$ coating were studied. SiC coatings of negligible thickness were formed at very low flow rates of hydrogen $\left(5 \times 10^{-5} \mathrm{~m}^{3} / \mathrm{min}\right)$ and $\mathrm{CH}_{3} \mathrm{SiCl}_{3}\left(1.0 \times 10^{-4} \mathrm{~m}^{3} / \mathrm{min}\right.$ of $\left.\mathrm{Ar}\right)$. Uneven coatings and brittle fibres were formed at very high concentrations of $\mathrm{CH}_{3} \mathrm{SiCl}_{3}\left(6 \times 10^{-4} \mathrm{~m}^{3} / \mathrm{min}\right.$ of $\left.\mathrm{Ar}\right)$. The flow rates of $\mathrm{CH}_{3} \mathrm{SiCl}_{3}$ and hydrogen were adjusted to get $\mathrm{SiC}$ fibre with smooth surface. The structure and morphology of $\mathrm{SiC}$ fibres were evaluated.
\end{abstract}

Keywords. SiC; CVD; continuous fibre; composite; deposition.

\section{Introduction}

Ceramic fibres are of great interest as reinforcements for metal matrix and ceramic matrix composites (MMCs and $\mathrm{CMCs}$ ), in defence and industrial applications. $\mathrm{SiC}$ has attractive properties like low density, high temperature strength, and resistance to oxidation and creep. Continuous fibres of $\mathrm{SiC}$ are prepared either by polymer pyrolysis or by chemical vapour deposition (CVD).

$\mathrm{SiC}$ fibres can be produced by pyrolysis of melt-spun polycarbosilane fibres. These fibres are used extensively to reinforce ceramics. The main disadvantage of this type of fibre is non-stoichiometry and presence of considerable amounts of free carbon and oxygen. At high temperatures the reaction between free carbon and oxygen causes decrease in properties. Stoichiometric chemical vapour deposited (CVD) coatings possess high strength and low porosity along with chemical purity. This is lacking in fibres made by sol-gel (Ling et al 1991) or melt-spinning (Edie and Dunham 1989) process. Stoichiometric and high purity $\mathrm{SiC}$ fibres have been made since mid 1960s by CVD on to a substrate like tungsten or carbon (Bunsell 1988).

In this process the core fibre $(\mathrm{W} / \mathrm{C})$ is fed into a glass reactor through a mercury contact and resistively heated by applying direct current. Mercury acts as gas tight seal and facilitates electrical resistance heating of the fibre. Hydrogen, argon, and silane vapours are fed into the reactor at about $1300^{\circ} \mathrm{C}$ (Debolt et al 1973; Fitzer et al 1973, 1975; Randon et al 1973; Crane and Kurkonis 1975) to get $\mathrm{SiC}$ deposition. Such fibres with different trade names (SCS fibres with $\mathrm{C}$ core from Textron Speciality Materi-

\footnotetext{
*Author for correspondence
}

als, Lowell, MA, USA; Sigma fibres with W core from Berghof, Germany; Trimarc1 with W core from Amercom, Inc., Atlantic Research Corporation, USA) are commercially available for last 15 years. Microstructure, microanalysis and creep properties of sigma fibres and SCS fibres were studied by Nutt and Wawner (1985), Martineau et al (1984), Ning et al (1993) and Dicarlo (1986).

Temperatures as high as $800^{\circ} \mathrm{C}$ have no appreciable effect on the properties, making CVD SiC monofilament a candidate for high temperature applications (Lindley and Jones 1975). The next generation aircraft engines need lighter high performance structural materials with high temperature capabilities (Sorensen 1993). Titanium based MMCs are being developed for use in aircraft turbine engines to operate in the temperature range from 600$800^{\circ} \mathrm{C}$. CVD processed $\mathrm{SiC}$ fibres with the substrate (either tungsten wire or a carbon monofilament) are used to reinforce these $\mathrm{Ti}$ based composites (Mizuhara et al 1997; Ellis and Gooch 1997). Some advantages of SiC fibre with tungsten core are: (i) tungsten wire of the appropriate diameter is available in relatively defect free, large spools, unlike carbon monofilament, (ii) the cost of producing $\mathrm{W}$-core $\mathrm{SiC}$ fibre is lower than $\mathrm{C}$-core $\mathrm{SiC}$, (iii) the modulus of $\mathrm{W}$-core $\mathrm{SiC}$ fibre is generally greater than that of C-core $\mathrm{SiC}$ fibre and this may be desirable in stiffness-critical applications (Gambone and Gundel 1997).

Ti-6Al-4V/sigma-1240(SiC) composites exhibit a high elastic stiffness (axial elastic modulus above $200 \mathrm{GPa}$ ) and fracture strength $\left(\mathrm{UTS} \approx 1.8 \mathrm{GPa}\right.$ ) and a $600^{\circ} \mathrm{C}$ creep rupture life of several thousand hours or more at $1 \mathrm{GPa}$ (Vancheeswaran et al 1998). We have recently taken up this work to develop CVD SiC fibre (with tungsten core) to use in $\mathrm{Ti}$ alloy $\mathrm{SiC}$ composites. Results of the prelimi- 
nary investigation on the chemical vapour deposition of $\mathrm{SiC}$ on tungsten filament are presented here.

\section{Experimental}

Figure 1 shows the schematic diagram of the apparatus used for the preparation of SiC fibre. As shown in figure 2 the glass reactor tube of length $60 \mathrm{~cm}$ is fixed with teflon supports on to laboratory stands. Initially a $19 \mu \mathrm{m}$ dia. tungsten filament was used as a substrate. The tungsten

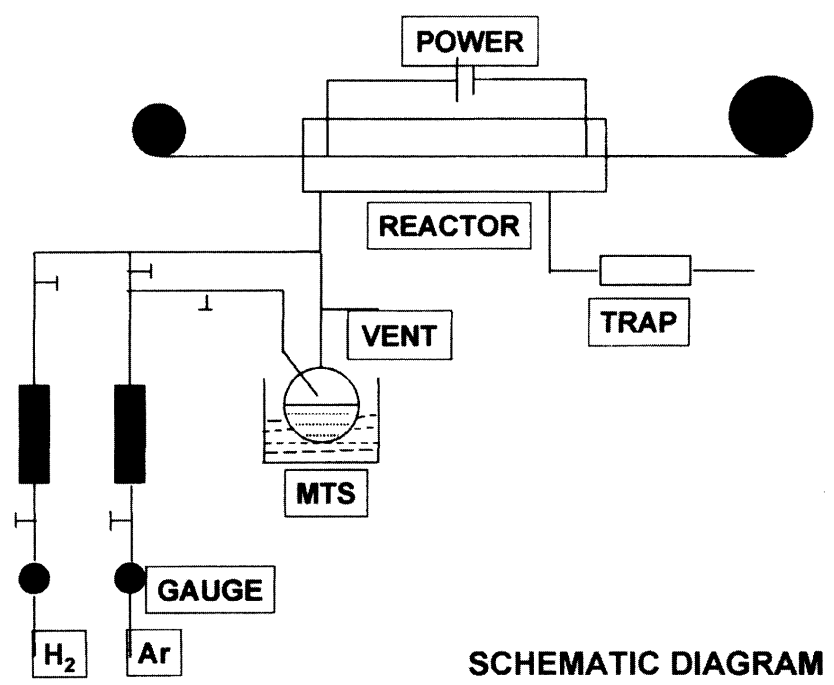

Figure 1. Schematic diagram of the typical CVD apparatus used for $\mathrm{SiC}$ coating on tungsten filament. filament wire from input spool is fed into the reactor from left end. After passing through the reactor for predetermined time, it get wound onto a plastic takeup spool of $25 \mathrm{~cm}$ outer diameter. As it becomes brittle after coating with $\mathrm{SiC}$, the fibre has to be wound on to a bigger diameter spool. The $\mathrm{W}$ filament wire is resistively heated by applying direct current from power source and through mercury contacts. Mercury acts as gas tight seal and provide electrical contact.

Methyl trichlorosilane (MTS) was used as reactant precursor because it contains silicon and carbon in stoichiometric proportions (Jin Choi et al 1997). The MTS bubbler was maintained on a constant temperature bath. As argon bubbles through MTS it carries away silane into the reactor. Hydrogen gas join the silane carrier gas before they enter the reactor. With MTS the basic reaction is expressed as

$$
\mathrm{CH}_{3} \mathrm{SiCl}_{3}(g) \stackrel{\mathrm{H}_{2}}{\longrightarrow} \mathrm{SiC}(s)+3 \mathrm{HCl}(g) .
$$

The exhaust gas mixture containing unspent silane, hydrogen, argon, decomposed products, and $\mathrm{HCl}$ was trapped by passing it through $\mathrm{NaOH}$ bubbler and water scrubber. The temperature of the $\mathrm{W}$ filament was controlled at required temperature by suitably adjusting the power input from d.c. power source. A precision optical pyrometer (Pyrometer Instrument Co., Inc., USA), capable of measuring the temperature of very thin filaments of the order of $0.0005^{\prime \prime}$ in diameter was used to monitor the temperature of $\mathrm{W}$ substrate.

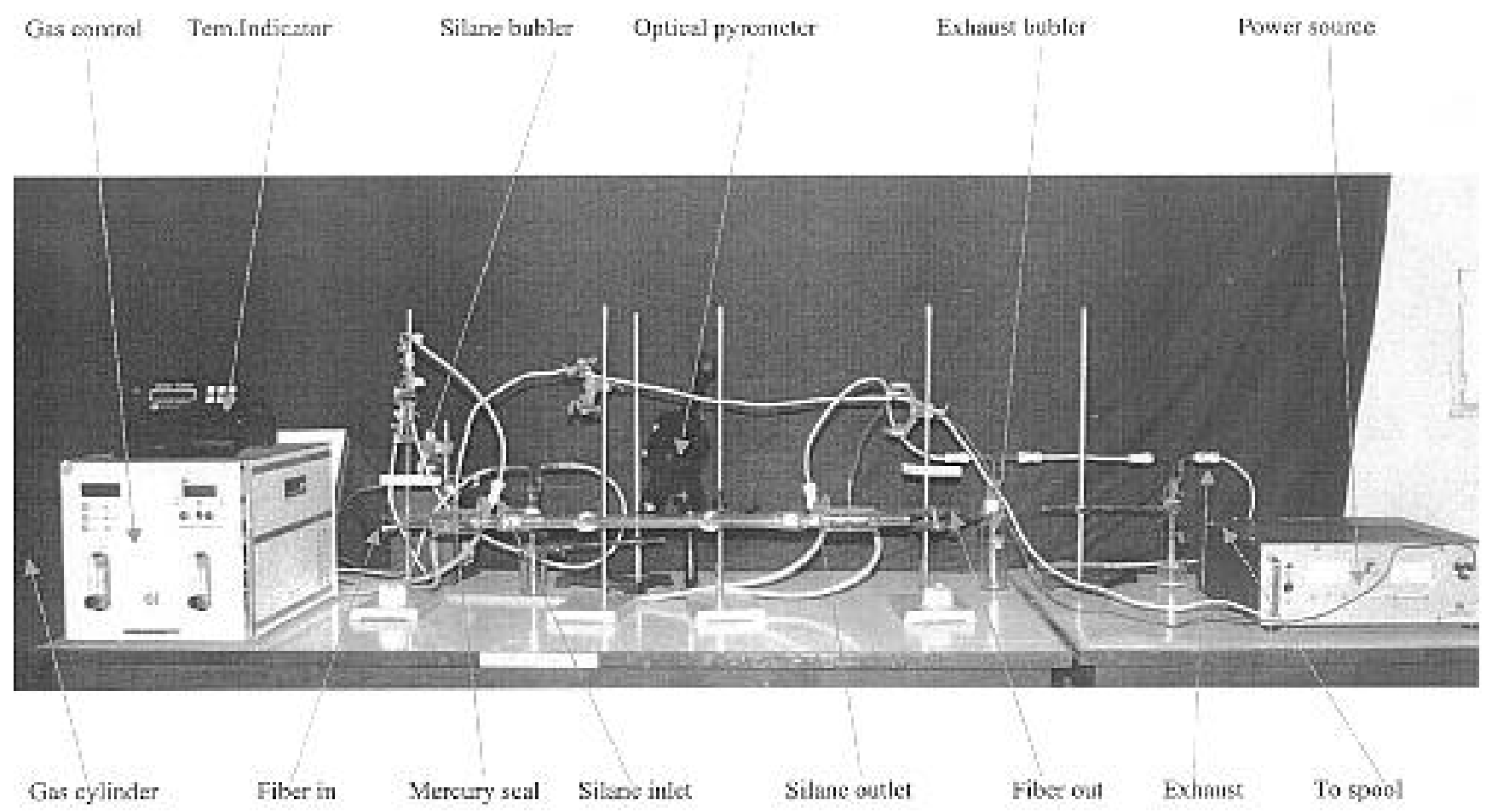

Figure 2. Photograph of CVD assembly with all accessories. 
Initially the decomposition of $\mathrm{SiC}$ was studied on stationary filaments. The free ends of the $\mathrm{W}$ filaments were tied with small weights to keep it straight. After SiC deposition for a residence time of about $20 \mathrm{sec}$ the filament was withdrawn from the reactor. The deposition was studied at different temperatures (1300, 1400 and $1500^{\circ} \mathrm{C}$ ). The effect of concentration of silane (MTS) and hydrogen on coating process was studied by varying the flow rates of hydrogen and argon. The structure and morphology of SiC fibre were studied through Leo scanning electron microscope (SEM). Scanning electron probe microanalysis (SEPMA) was carried out with CAMECA (model CAMEBAX-MICRO, France) equipment. To study the cross-section of the fibre a small piece of coated fibre was mounted in a steel tube with soldering lead.

\section{Results and discussion}

We experienced some difficulties during the initial experiments particularly with mercury seals and $\mathrm{W}$ filament loading. Pouring the mercury into the water cooled seals is a tough task. Since mercury is very heavy it easily enters into the reactor during pouring into seal and when-
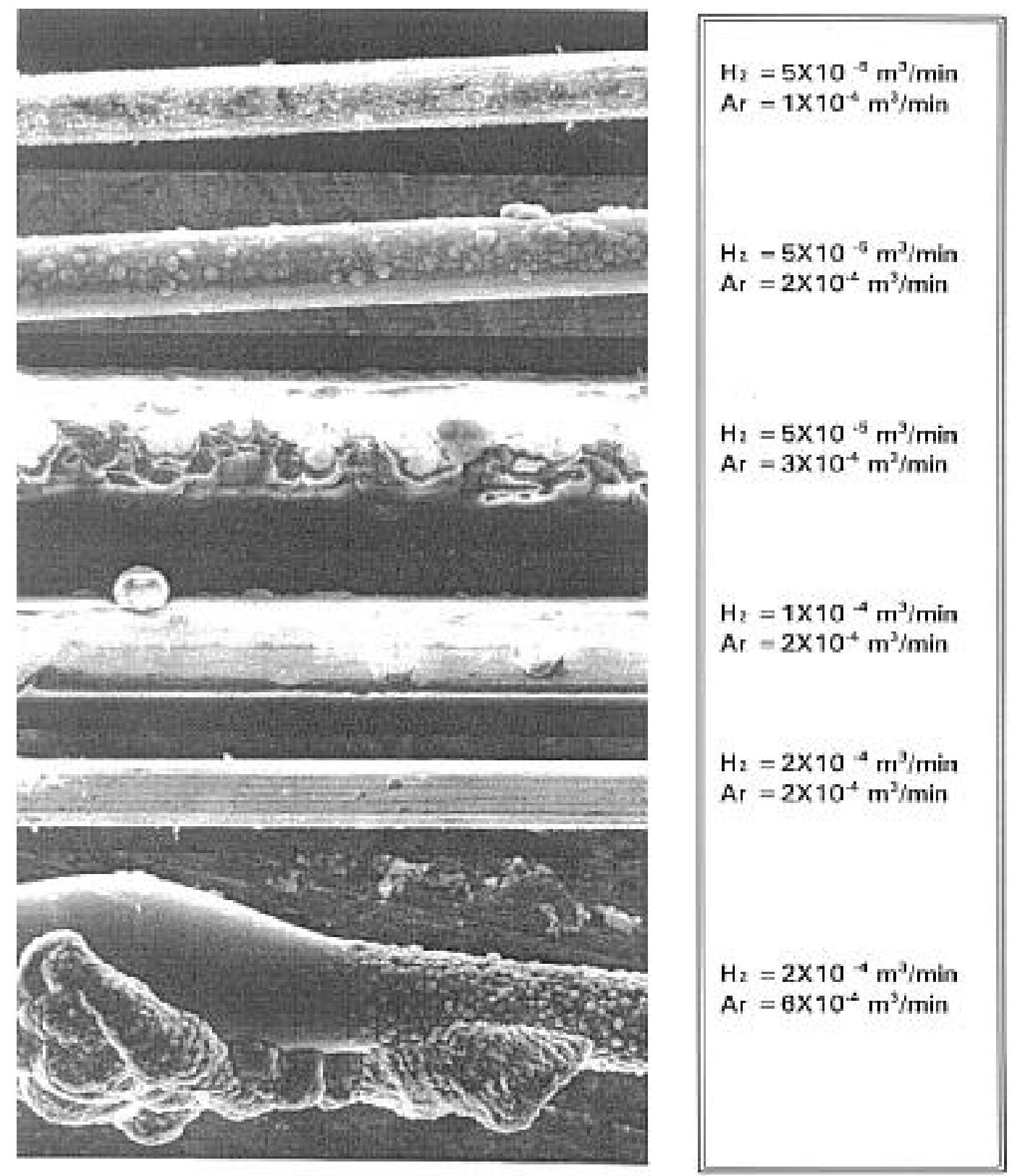

$\sqrt{111+\mathrm{m}}$

Figure 3. Effect of $\mathrm{H}_{2}$ and $\mathrm{CH}_{3} \mathrm{SiCl}_{3}$ concentrations on the formation of $\mathrm{SiC}$ coatings. 


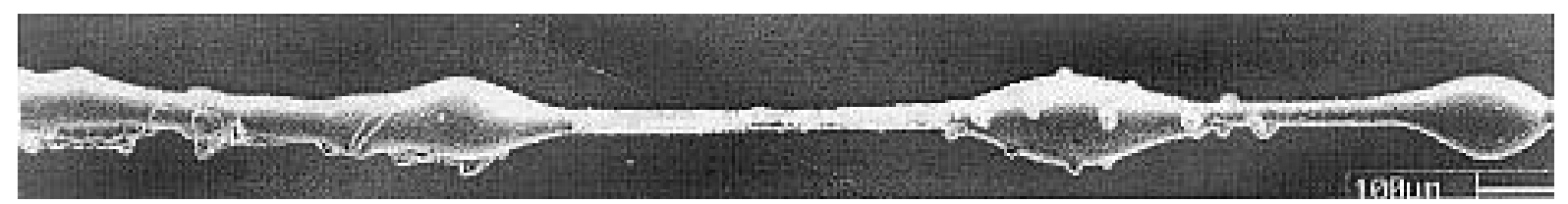

Figure 4. Uneven and wavy coatings formed at $0.2 \mathrm{Lpm}$ of hydrogen and $0.6 \mathrm{Lpm}$ of argon.

ever there is a slight change in the pressure inside the reactor. Since mercury is very toxic it should be removed from the reactor before starting the coating process. To facilitate easy feeding of mercury into the water cooled seal a special funnel with fine capillary is made. The capillary of the mercury seal is also altered. Loading of W filament through this fine seal capillary of the reactor tube is a difficult task. The initial single piece glass reactor is changed to three-piece reactor. Detachable water cooled mercury seals are attached with ground glass joints to the main reactor glass tube. With this apparatus it became easy to pull the $\mathrm{W}$ filament through the reactor. The handling of MTS is another tough job. It is air-sensitive and reacts with all plastic tubes, causes seizing, and galling of corks, lids and exhaust lines. Due to the closure of exhaust lines some time back pressure develops and reactant gasses gush out through mercury seals. Though extreme care is taken, pungent smell is experienced in the vicinity of CVD apparatus during the coating process.

In figure 3, the progress of $\mathrm{SiC}$ coating at $1300^{\circ} \mathrm{C}$ is shown. Initially the flow of hydrogen was kept constant at $5 \times 10^{5} \mathrm{~m}^{3} / \mathrm{min}$ to study the effect of concentration of silane. At $1 \times 10^{-4} \mathrm{~m}^{3} / \mathrm{min}$ flow of argon, very negligible amount of deposition was observed. This was due to very low concentration of MTS in argon carrier gas. When argon flow was increased to $2 \times 10^{-4} \mathrm{~m}^{3} / \mathrm{min}$ considerable increase in coating thickness was observed. Further increase in argon flow to $3 \times 10^{-4} \mathrm{~m}^{3} / \mathrm{min}$ resulted in thick and coarse grain coatings. The coarse grained surface of the fibre is detrimental to mechanical properties because the grain boundary of coarse grain acts as stress concentrator. In order to produce thicker coating, MTS concentration in $3 \times 10^{-4} \mathrm{~m}^{3} / \mathrm{min}$ argon is compensated by increasing the hydrogen flow from $5 \times 10^{-5} \mathrm{~m}^{3} / \mathrm{min}$ to $1 \times 10^{-4} \mathrm{~m}^{3} / \mathrm{min}$. Interestingly this combination has produced thicker and smooth surface coatings as can be seen in figure 3.

Further rise in hydrogen flow from $1 \times 10^{-4} \mathrm{~m}^{3} / \mathrm{min}$ to $2 \times 10^{-4} \mathrm{~m}^{3} / \mathrm{min}$ caused no coating. As the hydrogen flow is doubled it takes away the silane concentration so that no coating is formed on $\mathrm{W}$ substrate. To undo this effect further the flow of argon is increased to $0.6 \mathrm{Lpm}$ to provide more silane. Very thick and uneven (wavy) coatings were formed (figure 4) at high flow rates of hydrogen and argon (MTS). This fibre unlike other fibres is very brittle and became powder during handling. With high concentrations of hydrogen and MTS, hot spots were observed on W filament during the initial stages of coating. During
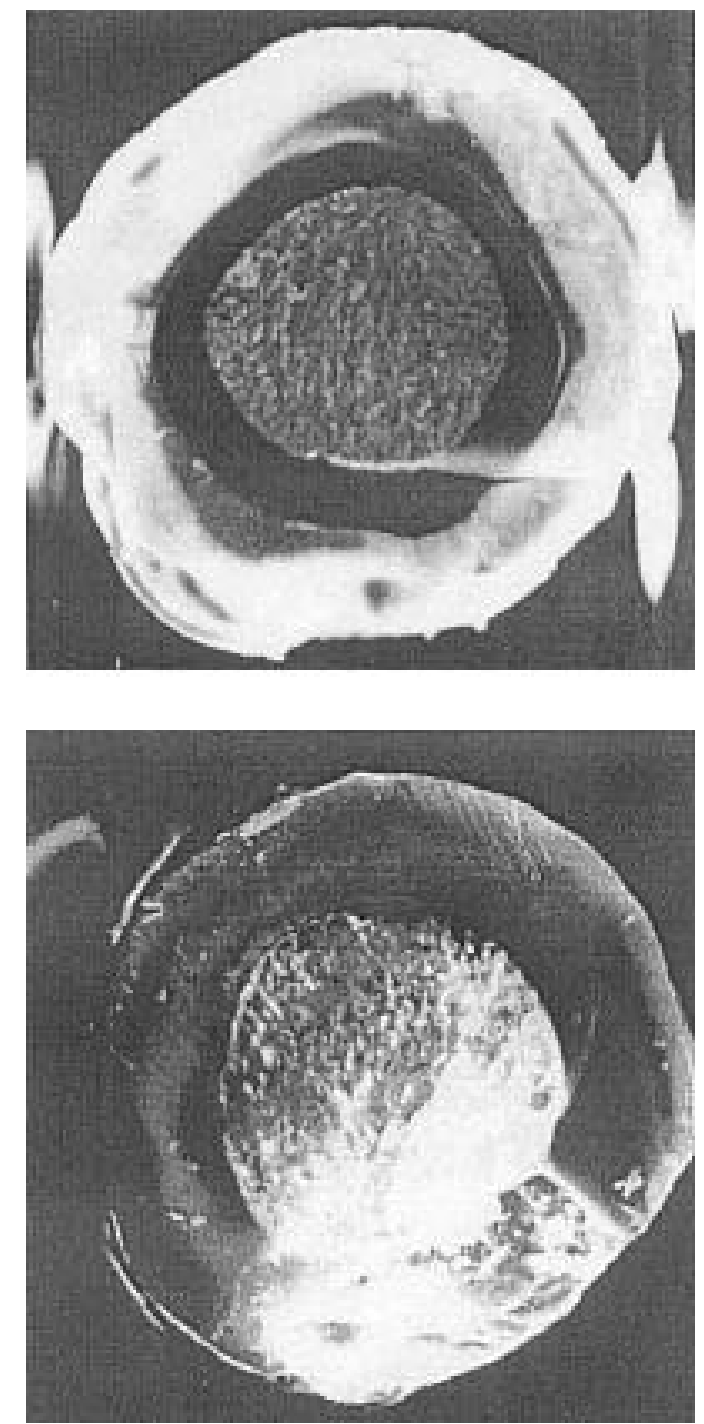

Figure 5. Cross-section of the fibre coated at $0.1 \mathrm{Lpm}$ of hydrogen and $0.2 \mathrm{Lpm}$ of argon.

initial stages of coating if thick coatings were formed at random places on substrate, the resistivity at those spots increased. This caused rise in temperature and fast build up of coating at such spots. This continued till the filament broke at some hot spot. Once hot spots were formed, the temperature of the remaining length of the filament decreased. Thick and fast growing coatings were formed at hot spots only causing uneven wavy coatings. This continued till the filament was broken at some hot spot. 
The fibre formed at $1 \times 10^{-4} \mathrm{~m}^{3} / \mathrm{min}$ hydrogen flow and $2 \times 10^{-4} \mathrm{~m}^{3} / \mathrm{min}$ argon flow was cut with a sharp blade. The cross-section of the broken fibre is shown in figure 5 . Since the surface is not polished it appeared like a cup and cone type fracture of a ductile fibre. Further $5 \mathrm{~mm}$ long fibre pieces were mounted by casting in a steel tube with solder lead. After polishing, the cross-section was examined by EPMA. Back scattered electron (BSE) image of the fibre cross-section is shown in figure 6. Tungsten in the substrate and silicon in the $\mathrm{SiC}$ coating were identified by X-ray mapping (figures $6 \mathrm{~b}-\mathrm{c}$ ). From the clean interface between $\mathrm{SiC}$ coating and $\mathrm{W}$ it appears that there is no reaction between $\mathrm{Si}$ and $\mathrm{W}$. However, there has been some difficulty in detecting the carbon in SiC coating. This could be due to the combined carbon and it is surrounded by heavy metal tungsten. However, carbon in the $\mathrm{SiC}$ coating was detected by auger electron spectroscopy

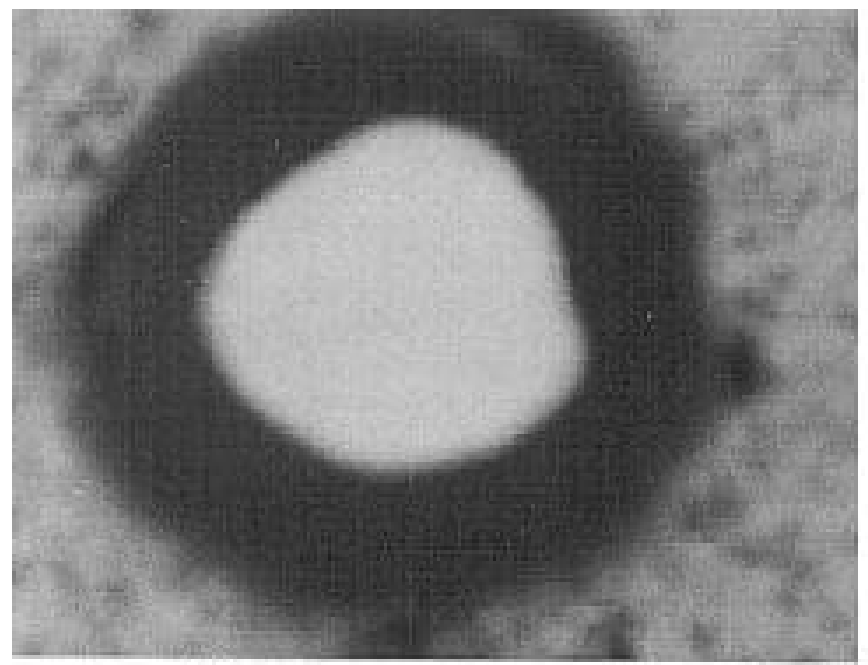

(a) (figure 7). Similarly no carbon was shown by Petitcorps et al (1988) in the X-ray microprobe analysis. They studied the structure and composition of $\sigma$ and SCS fibres. They have only shown silicon and tungsten lines scans for sigma SiC fibre. To confirm this we studied the structure of sigma fibre reinforced Ti alloy received from a commercial source. In this sample, free carbon from protective coating on the fibre only was detected but not the carbon from $\mathrm{SiC}$ deposition.

Further to confirm the presence of $\mathrm{SiC}$ in the CVD coating on $\mathrm{W}$ filament, a small piece of the coated fibre was treated with HF acid. No effect of HF acid on the coating was observed. If it was oxide of $\mathrm{Si}$ it must have dissolved in $\mathrm{HF}$ acid. HF treated and untreated fibres appeared similar. In figure $8 \mathrm{HF}$ treated $\mathrm{SiC}$ fibre is shown. No sign of reaction with HF acid was noticed. This along with EPMA and AES analyses confirmed that

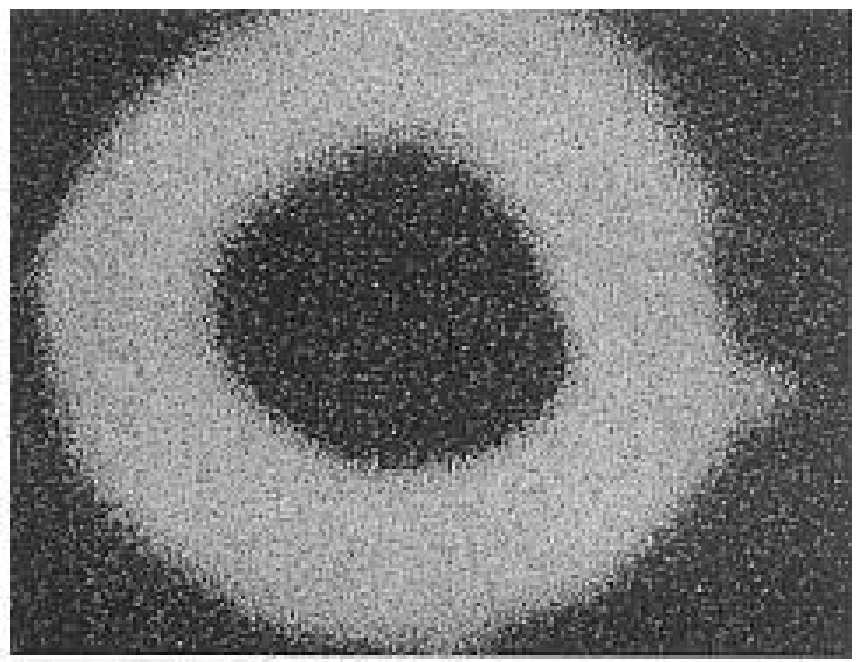

(b)

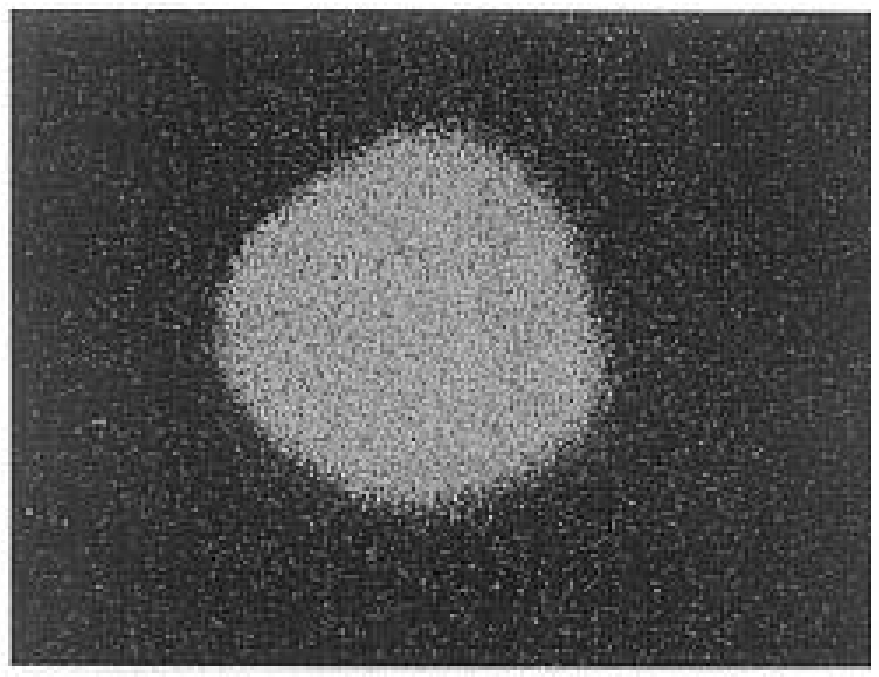

(c)

Figure 6. EPMA analysis of polished cross-section of SiC fibre: (a) BSE image, (b) Si X-ray map and (c) W X-ray map. 


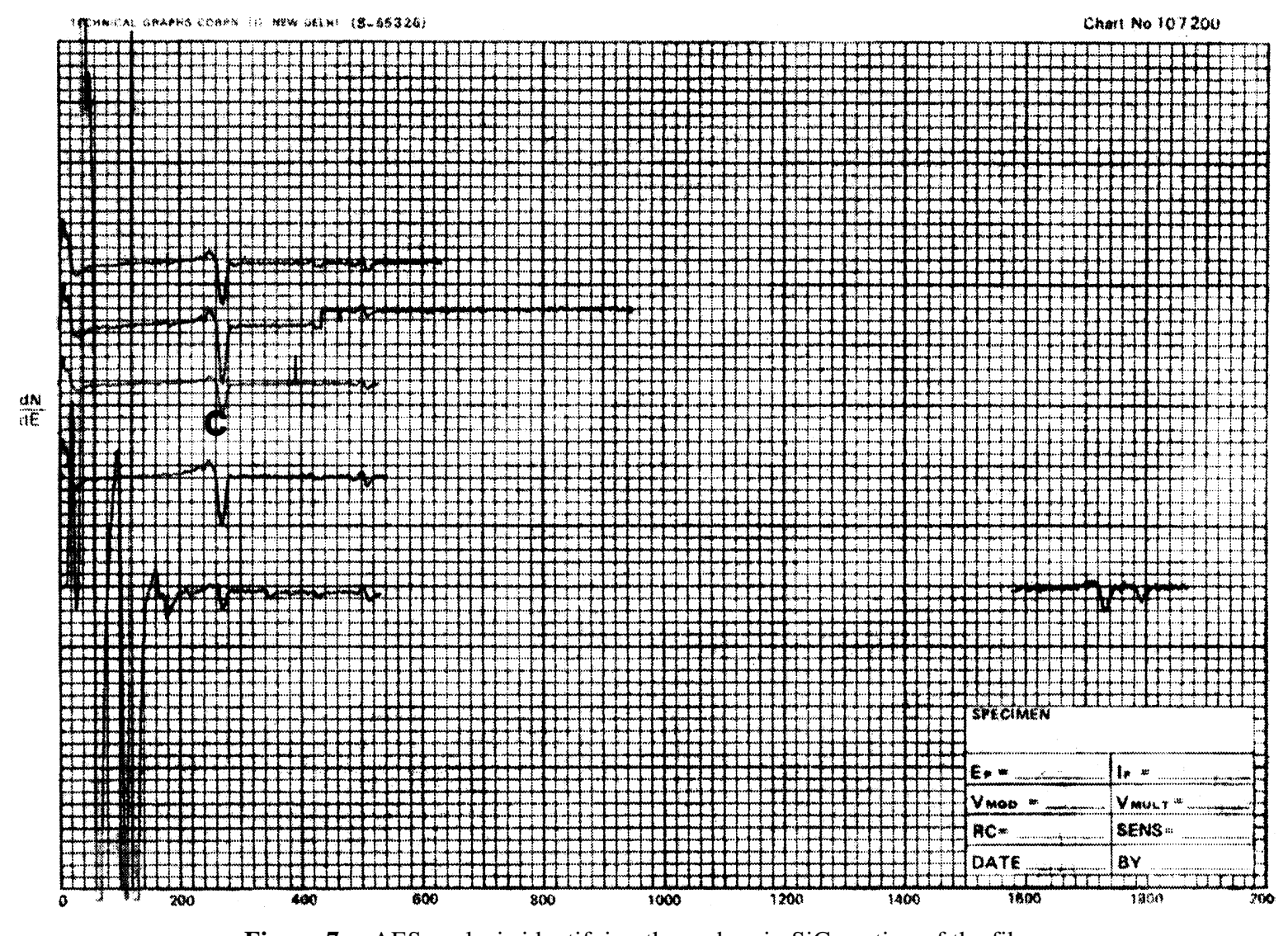

Figure 7. AES analysis identifying the carbon in $\mathrm{SiC}$ coating of the fibre.

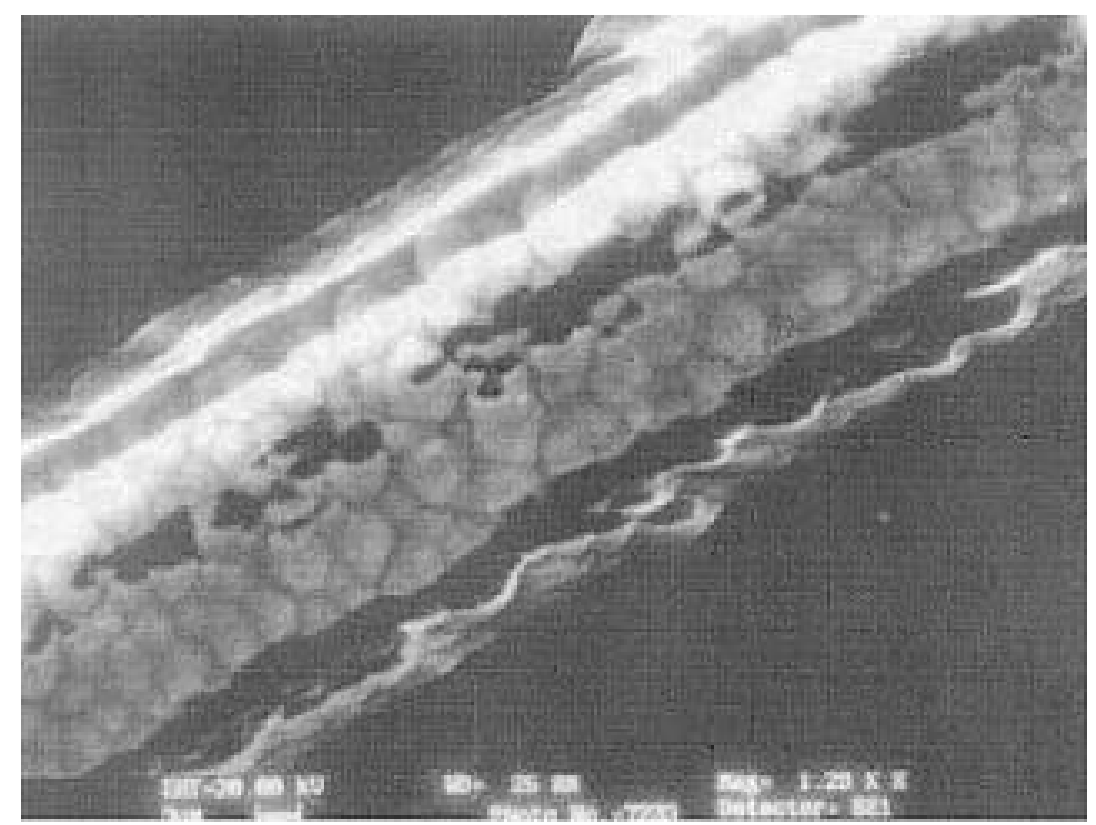

Figure 8. SiC fibre after treatment with $\mathrm{HF}$ acid. 
the coating formed was $\mathrm{SiC}$. Further rise in coating temperature to 1400 and $1500^{\circ} \mathrm{C}$ caused breaking of the filament during coating, and formation of brittle and uneven coatings.

\section{Conclusions}

A reactor for the formation of continuous SiC fibre by chemical vapour deposition on tungsten core filament has been successfully set up. To get smooth and evenly coated CVD SiC fibre, hydrogen flow and argon (carrying MTS) flow was found to be in the ratio of $1: 2$. High flow rates of hydrogen $\left(2 \times 10^{-4} \mathrm{~m}^{3} / \mathrm{min}\right)$ and argon $\left(6 \times 10^{-4} \mathrm{~m}^{3} /\right.$ min) lead to the isolated and uneven $\mathrm{SiC}$ coatings. Such wavy coatings are formed due to hot spots on the tungsten core filament. The cross-section of the fibre can be polished for analysis by mounting (casting) in solder lead. The analysis of carbon in CVD SiC with tungsten core is found to be difficult.

\section{Acknowledgements}

The authors thankfully acknowledge the financial support from the Defence Research and Development Organization, Ministry of Defence, New Delhi, in order to carry out the present study. They are also grateful to the Director, DMRL, Hyderabad, for his constant encouragement.

\section{References}

Bunsell A R (ed.) 1988 Fibre reinforcements for composite materials (Amsterdam, The Netherlands: Elsevier Science Publishers B.V.)

Crane R L and Kurkonis V J 1975 Am. Ceram. Soc. Bull. 54 184

Debolt H E, Kurkonis V J and Wawner Jr F E 1973 Silicon carbide (eds) R C Marshall, J W Faust and C E Rayan (Columbia, South Carolina: University of South Carolina Press) p. 168

Dicarlo J A 1986 J. Mater. Sci. 21217

Edie D D and Dunham M G 1989 Carbon 27647

Ellis M B D and Gooch T G 1997 Key engineering materials (Switzerland: Trans Tech Publications) 127-131 p. 343

Fitzer E, Kehr D and Sahebkar M 1973 Silicon carbide (eds) R C Marshall, J W Faust and C E Rayan (Columbia, South Carolina: University of South Carolina Press) p. 33

Fitzer E, Kehr D, Morin D and Sahebkar M 1975 Chemical vapour deposition, Fifth international conference proceedings (eds) J M Bolcher Jr, H S Hintermann and L H Hall (New Jersey: The Electrochemical Society, Inc.) p. 589

Gambone M L and Gundel D B 1997 Key engineering materials (Switzerland: Trans Tech Publications) 127-131 p. 1251

Jin Choi B, Wonpark D and Ryong Kim D 1997 J. Mater. Sci. Lett. 1633

Lindley M W and Jones B F 1975 Nature 255474

Ling D A, Desai P and Abhiraman A S 1991 Polym. Mater. Sci. Eng. 64381

Martineau P, Lahaye M, Pailler R, Naslain R, Couzi M and Cruege F 1984 J. Mater. Sci. 192731

Mizuhara Y, Hashimoto K, Nakatami H and Shimada Y 1997 Structural intermetallics (eds) M V Nathal et al (Warrendale, PA: The Minerals, Metals \& Materials Society) p. 929

Ning X J, Pirouz P and Farmer S C 1933 J. Am. Ceram. Soc. 76 2033

Nutt S R and Wawner F E 1985 J. Mater. Sci. 201953

Petitcorps Y Le, Lahaye M, Pailler R and Naslain R 1988 Composites Sci. \& Tech. 3231

Randon J L, Slama G and Vignes A 1973 Silicon carbide (eds) R C Marshall, J W Faust and C E Rayan (Columbia, South Carolina: University of South Carolina Press) p. 386

Sorensen J 1993 Structural intermetallics (eds) R Darolia et al (Warrendale, PA: The Minerals, Metals \& Materials Society) p. 717

Vancheeswaran R, Elzey D M, Kunze J M and Wadley H N G 1998 Mater. Sci. \& Engg. A244 49 